\title{
Fundus autofluorescence and spectral-domain optical coherence tomography findings suggesting tissue remodelling in retinal pigment epithelium tear
}

\author{
Albert Caramoy, Sascha Fauser, Bernd Kirchhof
}

Department of Vitreoretinal Surgery, Center of Ophthalmology, University of Cologne, Cologne, Germany

\section{Correspondence to} Dr med. Albert Caramoy, Department of Vitreoretinal Surgery, Center of Ophthalmology, University of Cologne, Kerpenerstr. 62 , 50924 Cologne, Germany; acaramoy@yahoo.co.uk

Accepted 10 June 2012

\section{ABSTRACT}

Aim To study tissue remodelling and wound healing after retinal pigment epithelium (RPE) tears due to age-related macular degeneration.

Methods Retrospective longitudinal study of 36 eyes (33 patients) with RPE tears. Imaging was performed using fundus autofluorescence (FAF) $(\lambda=488 \mathrm{~nm})$ and spectral-domain optical coherence tomography (SDOCT). Presence of intraretinal hyper-reflective dots in SDOCT, which correlated with hyperfluorescent dots in FAF, indicating RPE migration was studied. Morphology of subretinal mass and RPE layer integrity in the RPE denuded area over time were examined.

Results 7 of 36 eyes (19.4\%) showed patchy or hazy hyperfluorescent areas in $\mathrm{FAF}$, and the majority of eyes (83.3\%) showed hyper-reflective dots, which possibly represent intraretinal RPE migration and hard exudates. Homogenous subretinal mass was encountered in about half of all cases. In one case $(2.8 \%)$, the RPE layer proliferated and covered the defect.

Conclusions SD-OCT and FAF showed a considerable amount of RPE proliferation, migration and repopulation. Intraretinal RPE migration did not form a functional RPE layer. A small defect might be repaired by cell proliferation. But this RPE proliferation is not sufficient to cover large defects.

\section{INTRODUCTION}

One devastating complication of exudative agerelated macular degeneration is a retinal pigment epithelium (RPE) tear. In an RPE tear, the pigment epithelium sheath becomes separated from the neurosensoric retina. Although photoreceptor cells are not able to function during this separation, ${ }^{1}$ they can survive up to 325 days after an RPE tear. ${ }^{2}$ This knowledge is essential for planning therapies such as macular translocation ${ }^{3} 4$ or autologous pigment epithelium and choroid transplantation. ${ }^{56}$ These therapies are successful only in some cases but carry a high risk. Therefore, it is crucial to select patients who probably would benefit from surgery.

Some case reports on RPE tears reported spontaneous reattachments of the RPE using timedomain optical coherence tomography (OCT). ${ }^{7}$ In this study, we analyse the use of fundus autofluorescence (FAF) and spectral-domain optical coherence tomography (SD-OCT), which is superior to time-domain OCT, to enhance the current knowledge on remodelling process in RPE tears. If it is possible to predict this process, surgery would not be necessary for certain patients. In this paper, we examined the wound healing process of RPE tears to better understand which patients would have the greatest chance for such a reattachment.

\section{PATIENTS AND METHODS}

A retrospective data analysis was conducted of patients at the University Eye Hospital of Cologne, Germany, from the year 2001 to 2011. Eighty-eight patients with RPE tears can be identified from this time period. Among these patients, 33 patients were included in the study; the rest of them not having FAF and SD-OCT images were excluded. In three patients (patients 1,2 and 30) the acute event of RPE tear happened before the introduction of SD-OCT in our clinic in 2008 (approximately 1 year before); therefore, SD-OCT measurements were performed since 2008. Two eyes of two patients (patient 5 and the left eye of patient 9) were part of a microperimetric study reported before. ${ }^{5}$ Approval from the local ethic committee was sought and waived due to the retrospective nature of the study. Informed consent was obtained from each patient after explanation of the nature and possible consequences of the study. The study followed the tenets of the Declaration of Helsinki.

Each patient underwent a routine ophthalmological examination, including best corrected visual acuity using Snellen charts, biomicroscopy and fluorescein and/or indocyanine green angiography. SD-OCT and FAF were performed at every visit.

SD-OCT was carried out with a Spectralis HRA +OCT device (Heidelberg Engineering, Heidelberg, Germany) that was equipped with an eye-tracking system for the simultaneous acquisition of nearinfrared reflectance $(\lambda=815 \mathrm{~nm})$ and SD-OCT images. This simultaneous SD-OCT imaging was carried out with an illumination wavelength of $870 \mathrm{~nm}$ and an acquisition speed of 40000 A-scans per second. For each eye, a standard protocol of SDOCT imaging was used; this comprised a star of 6 B-scans (angle between scans was $30^{\circ}$ ) and a block containing $37 \mathrm{~B}$-scans $\left(20^{\circ} \times 15^{\circ}\right.$, distance between B-scans: $125 \mu \mathrm{m})$. For these purposes, 19 SD-OCT images were averaged to obtain the final image.

FAF was acquired using the same device (excitation at $\lambda=488 \mathrm{~nm}$, emission $500-700 \mathrm{~nm}$ ). The field of view size encompassed $30^{\circ} \times 30^{\circ}$, with an image resolution of $768 \times 768$ pixels.

Grading of RPE tear was performed using grading system as suggested by Sarraf et al. ${ }^{9}$ According to this grading system, RPE tears are graded based on the greatest length of defect (hypofluorescent area in FAF) in the vector direction of the tear and foveal involvement. For this measurement, the FAF 
images at the first presentation of RPE tear were used because tear border was the easiest to be demarcated. Visual acuity was transformed into logarithm of the minimum angle of resolution (LogMAR).

Statistical analyses were done using PASW Statistics 18 (Predictive Analytics Software, V.18.0.0, IBM, Armonk, New York, USA). Demographic characteristics of the population are described with summary statistics, including frequency and percentage for categorical data. Continuous data are presented with mean $\pm \mathrm{SD}$ or with median. Correlation between ordinal and interval data (as in between RPE tear grade and LogMAR BCVA) was performed using Spearman's rank order correlation coefficient. p Value $<0.05$ was deemed as statistically significant.

\section{RESULTS}

In all, 36 eyes of 33 patients were identified as having RPE tears. Demographic characteristics of these patients are shown in table 1. Among 33 patients, 12 were men and 21 were women. The mean age was 76 8.3 (range $57-91$ ) years old. The majority of patients $(66.67 \%)$ had severe RPE tears, that is, grade 3 or 4 according to Sarraf et al. ${ }^{9}$ In the follow-up time, change in RPE tears grade is observed only in one patient (2.8\%), that is, a case of self-healing RPE tear presented below. In our findings, there was no correlation between RPE tears severity grade and LogMAR visual acuity at the first presentation $\left(r_{s}=0.102\right.$, $\mathrm{p}=0.553)$. Eighteen eyes (50\%) received anti-vascular endothelial growth factor therapy prior to the RPE tear. Mean number of

Table 1 A summary of demographic characteristics

\begin{tabular}{|c|c|c|c|c|c|c|c|c|c|c|c|}
\hline $\begin{array}{l}\text { Patient } \\
\text { no. }\end{array}$ & Eye & $\begin{array}{l}\text { RPE tear } \\
\text { grade }\end{array}$ & Age & $\begin{array}{l}\text { BCVA } \\
\text { (LogMAR) } \\
\text { at first visit }\end{array}$ & $\begin{array}{l}\text { BCVA } \\
\text { (LogMAR) } \\
\text { at last visit }\end{array}$ & $\begin{array}{l}\text { Therapy prior } \\
\text { to RPE tear (no.) }\end{array}$ & $\begin{array}{l}\text { Time after } \\
\text { RPE tears } \\
\text { (d) }\end{array}$ & $\begin{array}{l}\text { Total } \\
\text { follow-up } \\
\text { time (d) }\end{array}$ & $\begin{array}{l}\text { FAF in } \\
\text { RPE denuded } \\
\text { area }\end{array}$ & HRDs & $\begin{array}{l}\text { Subretinal } \\
\text { mass at last } \\
\text { follow-up }\end{array}$ \\
\hline 1 & OS & 2 & 86 & 0.35 & 1.4 & Bevacizumab (1) & 1938 & 2092 & Dark & No & Yes \\
\hline 2 & OD & 3 & 74 & 0.48 & 1.5 & Bevacizumab (1) & 1681 & 1861 & $\begin{array}{l}\text { Hazy } \\
\text { hyperfluorescent }\end{array}$ & Yes & No \\
\hline 3 & OS & 3 & 90 & 1.30 & 1.05 & None & 882 & 1911 & $\begin{array}{l}\text { Dark, patchy } \\
\text { hyperfluorescent on } \\
\text { the border }\end{array}$ & No & Yes \\
\hline 4 & OD & 3 & 77 & 0.4 & 0.7 & Bevacizumab (4) & 325 & 329 & Dark & Yes & Yes \\
\hline 5 & OS & 4 & 80 & 0.7 & 1.3 & Ranibizumab (3) & 330 & 425 & Dark & No & No \\
\hline 6 & OD & 3 & 76 & 1.3 & NA & None & 222 & 1455 & Dark & Yes & Yes \\
\hline 7 & OS & 4 & 73 & 0.45 & 1.4 & None & 212 & 215 & Dark & Yes & No \\
\hline 8 & OD & 2 & 70 & 0.15 & 0.1 & None & 1041 & 1344 & Dark & Yes & No \\
\hline \multirow[t]{2}{*}{9} & $\mathrm{OD}$ & 3 & 72 & 0.45 & 0.5 & None & 372 & 1302 & Dark & Yes & Yes \\
\hline & OS & 4 & & 0.5 & 0.7 & $\begin{array}{l}\text { Ranibizumab (3), } \\
\text { Bevacizumab (1) }\end{array}$ & 226 & 1302 & $\begin{array}{l}\text { Patchy } \\
\text { hyperfluorescent }\end{array}$ & Yes & No \\
\hline 10 & OD & 1 & 82 & 0.7 & 1.5 & Ranibizumab (3) & 732 & 1671 & Dark & Yes & Yes \\
\hline 11 & OD & 2 & 65 & 0.3 & 1.5 & Ranibizumab (2) & 52 & 168 & Dark & Yes & No \\
\hline \multirow[t]{2}{*}{12} & OD & 3 & 85 & 0.56 & NA & None & 53 & 54 & Dark & Yes & No \\
\hline & OS & 4 & & 0.2 & NA & None & NA & 54 & Dark & Yes & No \\
\hline 13 & OS & 2 & 80 & 0.55 & 0.58 & Ranibizumab (3) & 111 & 455 & Dark & No & No \\
\hline 14 & $\mathrm{OD}$ & 4 & 75 & 0.6 & 0.2 & None & 1165 & 3405 & $\begin{array}{l}\text { Patchy } \\
\text { hyperfluorescent }\end{array}$ & Yes & No \\
\hline 15 & OD & 4 & 78 & 0.45 & NA & Ranibizumab (2) & NA & NA & Dark & Yes & Yes \\
\hline 16 & OS & 3 & 86 & 1 & 1 & None & 128 & 337 & Dark & Yes & Yes \\
\hline 17 & $\mathrm{OD}$ & 2 & 68 & 0.4 & 0.4 & None & 104 & 1701 & Dark & Yes & Yes \\
\hline 18 & OS & 2 & 62 & 0.3 & 0.3 & None & 109 & 946 & $\begin{array}{l}\text { Patchy } \\
\text { hyperfluorescent }\end{array}$ & Yes & Yes \\
\hline 19 & OD & 3 & 81 & 1.30 & 1.7 & Ranibizumab (3) & 333 & 1262 & Dark & Yes & No \\
\hline 20 & OD & 4 & 83 & 1.3 & NA & $\begin{array}{l}\text { rtPA+SF6 (1), } \\
\text { ranibizumab (1) }\end{array}$ & NA & 819 & Dark & No & No \\
\hline 21 & OD & 1 & 79 & 0.60 & 0.1 & $\begin{array}{l}\text { rtPA+SF6+ } \\
\text { bevacizumab (2) }\end{array}$ & 670 & 925 & Dark & Yes & Yes \\
\hline \multirow[t]{2}{*}{22} & OD & 4 & 81 & 0.7 & 1.5 & None & 593 & 1648 & Dark & Yes & No \\
\hline & OS & 4 & & 0.26 & 1.3 & Ranibizumab (1) & 32 & 1648 & Dark & Yes & No \\
\hline 23 & OD & 2 & 72 & 1 & 1.4 & Ranibizumab (3) & 77 & 231 & Dark & No & No \\
\hline 24 & OS & 3 & 91 & 0.6 & 1.3 & Ranibizumab (3) & 895 & 992 & Dark & Yes & No \\
\hline 25 & OS & 4 & 85 & 0.6 & NA & Ranibizumab (2) & NA & NA & Dark & Yes & Yes \\
\hline 26 & OD & 1 & 71 & 0.6 & 0.6 & None & 110 & 2438 & $\begin{array}{l}\text { Patchy } \\
\text { hyperfluorescent }\end{array}$ & Yes & No \\
\hline 27 & OS & 1 & 83 & 0.8 & 1 & None & 663 & 896 & Dark & Yes & Yes \\
\hline 28 & OD & 4 & 61 & 0.3 & 0.4 & None & 317 & 709 & Dark & Yes & Yes \\
\hline 29 & OD & 4 & 57 & 0.7 & 0.7 & None & 158 & 278 & $\begin{array}{l}\text { Patchy } \\
\text { hyperfluorescent }\end{array}$ & Yes & No \\
\hline 30 & OS & 4 & 68 & 0.3 & 0.6 & Ranibizumab (3) & 1334 & 1996 & Dark & Yes & No \\
\hline 31 & OD & 4 & 75 & 1.5 & 1.5 & $\begin{array}{l}\text { rtPA+SF6 (1), } \\
\text { ranibizumab (5), } \\
\text { bevacizumab (2) }\end{array}$ & NA & 810 & Dark & Yes & Yes \\
\hline 32 & OD & 1 & 67 & 1 & NA & None & NA & NA & Dark & Yes & No \\
\hline 33 & OD & 4 & 72 & 0.2 & NA & None & NA & NA & Dark & Yes & No \\
\hline
\end{tabular}

BCVA, best corrected visual acuity; d, days; FAF, fundus autofluorescence; HRDs, hyper-reflective dots; LogMAR, logarithm of the minimum angle of resolution; NA, not applicable; OD, the right eye; OS, the left eye; RPE, retinal pigment epithelium; rtPA, recombinant tissue plasminogen activator; SF6, sulphur hexafluoride $20 \%$. 
follow-up visits was $9.5 \pm 7.4$ and median time after RPE tear was 325 days and median follow-up time was 969 days.

Subretinal blood was identified in 4 of 36 eyes (11.1\%) at the first presentation. The peripheral torn edge of the RPE layer presented as a sharp border in recent RPE tears. Over time, these edges became hazier and could be less well demarcated. FAF of RPE tears showed a hypofluorescent area in the RPE denuded zone, indicating non-existing RPE. In 7 of 36 eyes (19.4\%), hazy or speckled hyperfluorescent areas appeared in this region over time. The first hazy or speckled hyperfluorescent areas were seen approximately 3 months after the acute event of RPE tear. When correlated with SD-OCT, dots of hyper-reflective materials were visible in the retina. These hyper-reflective dots (HRDs) had various diameters ranging from 10 to $120 \mu \mathrm{m}$ on SD-OCT images. Clumps of HRDs were arranged as chains in the posterior segment of the photoreceptor layer (POS) after the acute event of an RPE tear. These HRDs were present irrespective of the presence of subretinal or intraretinal fluid.
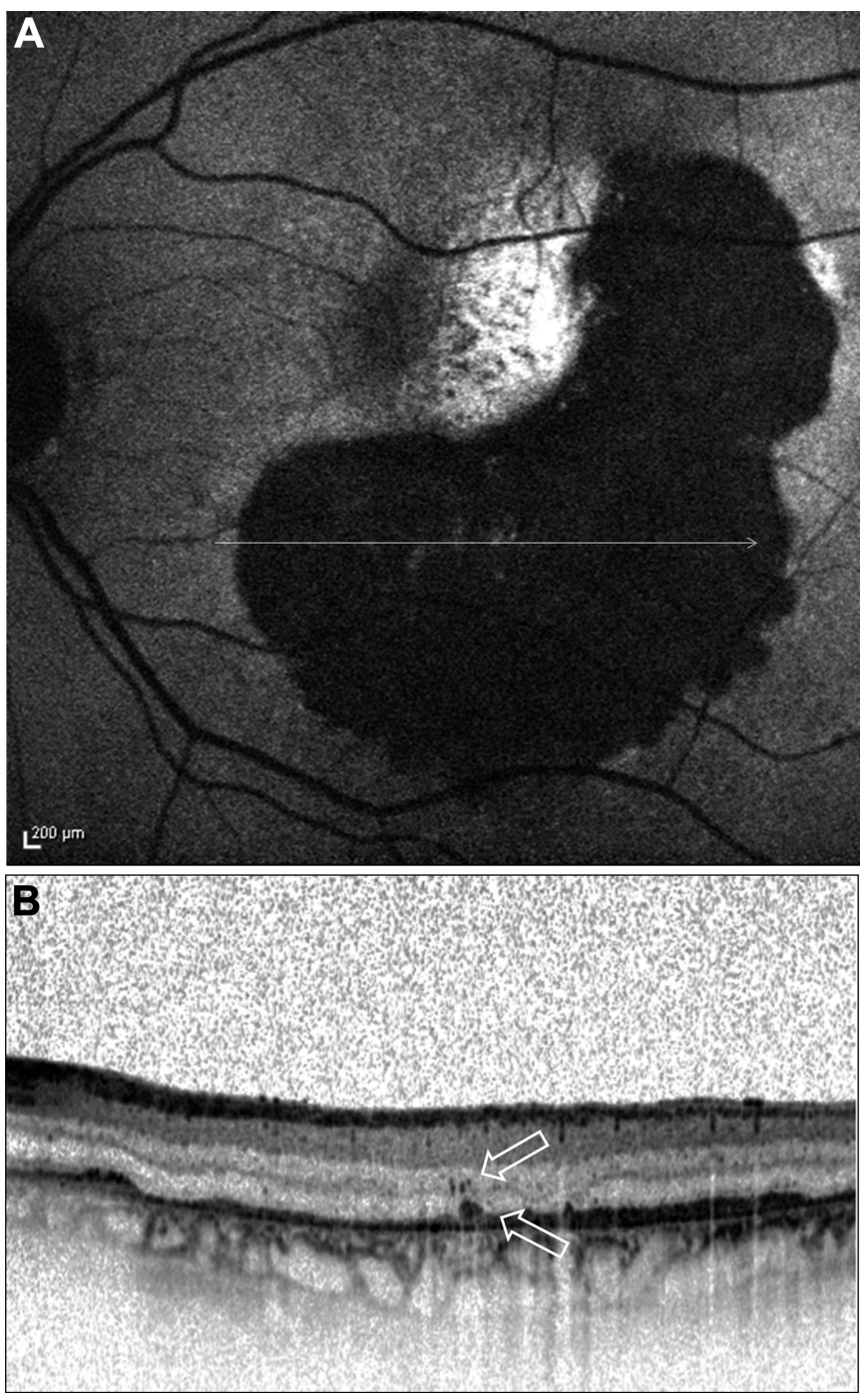

Figure 1 A retinal pigment epithelium (RPE) tear 5 months after the acute event. Fundus autofluorescence $(A)$ image showed patchy hyperfluorescent spots in the RPE denuded area. The corresponding spectral-domain optical coherence tomography (B) showed hyperreflective dots (arrows). Shadowing effect posterior to the hyperreflective dots can be seen.
HRDs arranged around intraretinal cysts were mostly small in diameter (approximately $10 \mu \mathrm{m}$, presumably intraretinal hard exudates), while those located in the outer retinal layers were large (up to $120 \mu \mathrm{m}$ ) and showed a high backscattering effect. These large HRDs created a shadowing effect; presumably they represented migrating intraretinal RPE cells, if no intraretinal or subretinal fluid was present (figure 1). These HRDs were identified in 30 of 36 eyes (83.3\%) on SD-OCT scans. They were frequently encountered in the outer retinal layers and sometimes in the inner retinal layers. Some HRDs in the RPE denuded area were located directly on Bruch's membrane. In FAF images, these migrating RPE cells appeared hyperfluorescent, while hard exudates appeared hypofluorescent (figure 2).

The border of the RPE denuded area presented as speckled hyperfluorescent areas in the FAF. In the corresponding SD-OCT, curled or redundant RPE layers were seen. Large HRDs with backscattering were frequently present in this region.

Overall, 15 of 36 eyes (41.7\%) showed a homogenous subretinal mass in the RPE denuded area. These subretinal masses showed choroidal hyper-reflectivity as a sign of not having
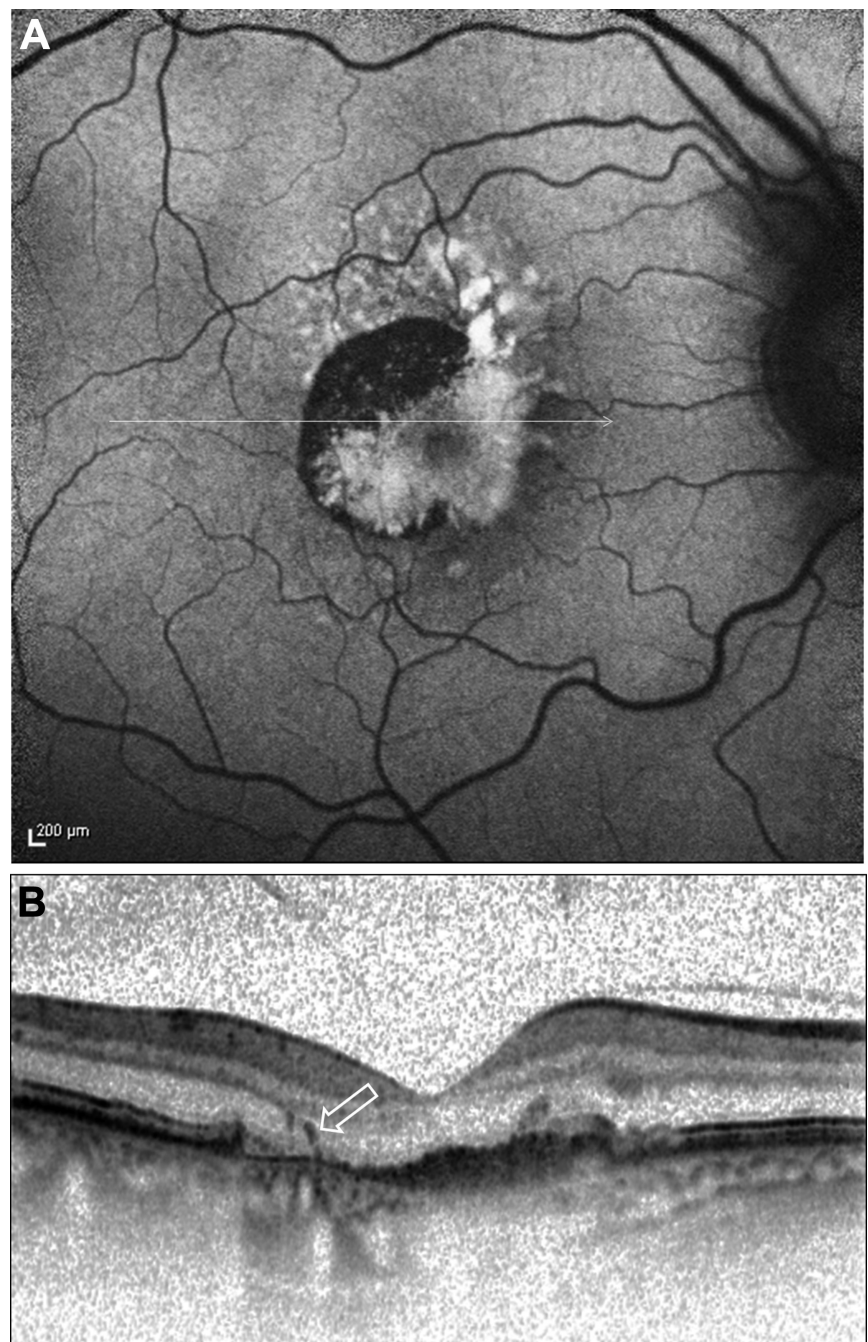

Figure 2 A retinal pigment epithelium (RPE) tear 1 year and 2 months after the acute event. Fundus autofluorescence $(A)$ image of retinal pigment epithelium tear showed hyperfluorescent spots in the RPE denuded area. The corresponding spectral-domain optical coherence tomography image (B) showed hyper-reflective dots (arrow), indicating intraretinal RPE migration. 
Figure 3 A retinal pigment epithelium (RPE) tear 3 years after the acute event. Colour fundus photography $(A)$ of RPE tear. The white star indicated the presence of intraretinal hard exudates, which appeared hypofluorescent in the corresponding fundus autofluorescence (B) image. The area between the two arrowheads (C) showed the enhanced choroidal hyper-reflectivity. A homogenous subretinal mass can also be seen. (D) The intraretinal hard exudates (star in A and B) are presented as a large hyper-reflective lesion with shadowing effect (white arrow). This figure is produced in colour in the online journal-please visit the website to view the colour figure.
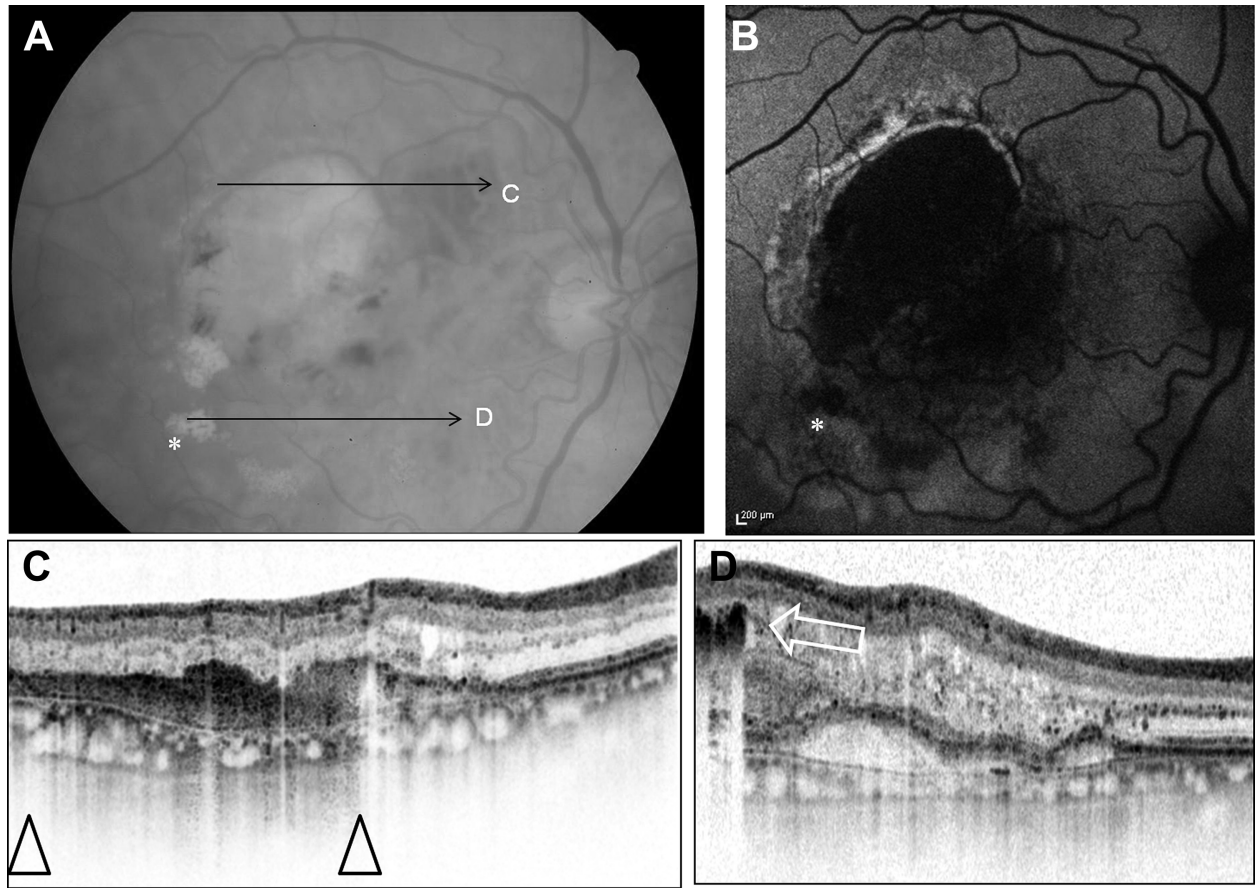

melanin to absorb light in the SD-OCT. The corresponding FAF images showed hypofluorescent area, indicating a lack of lipofuscin. These materials were in SD-OCT mostly homogenous and did not form a single layer (figure 3 ).

In 1 of 36 eyes (2.8\%), the RPE tear was relatively small (patient 8). In follow-up visits, the defect in the RPE denuded area was covered with a layer of RPE cells. The hyper-reflective area indicated that the RPE denuded area constantly dissipated over time in the corresponding near infrared image. In SD-OCT, a new RPE layer was identified (figure 4). The corresponding FAF image in this area remained hypofluorescent, possibly indicating that this new RPE layer lacked lipofuscin.

\section{DISCUSSION}

Wound healing and RPE proliferation of RPE tears have been studied by several authors. ${ }^{6}{ }^{10}$ In time domain OCT, the reattachment of the RPE layer and RPE repopulation have been documented. ${ }^{7}$ We also found a considerable tissue remodelling over several years using FAF and SD-OCT. We saw RPE repopulation in one case, that is, a small RPE tear which is in line with other reports. ${ }^{8} 10$ These new RPE cells lacked lipofuscin, as shown in hypofluorescent FAF.

Histological studies of RPE tears also reported RPE cell migration and proliferation. In a case reported by Green et al, the RPE proliferated to the underside of the ripped basement
Figure 4 A case of self-healing retinal pigment epithelium (RPE) tear. The fundus autofluorescence $(A)$ showed a small RPE defect, which corresponds to an area of enhanced choroidal hyperreflectivity (B) (between arrowheads). Two and a half years after the RPE denuded area has been covered by a single RPE layer (C and D). The black star represents a small atrophy, used as an anatomical landmark, ensuring approximately the same level of SDOCT measurements over time.
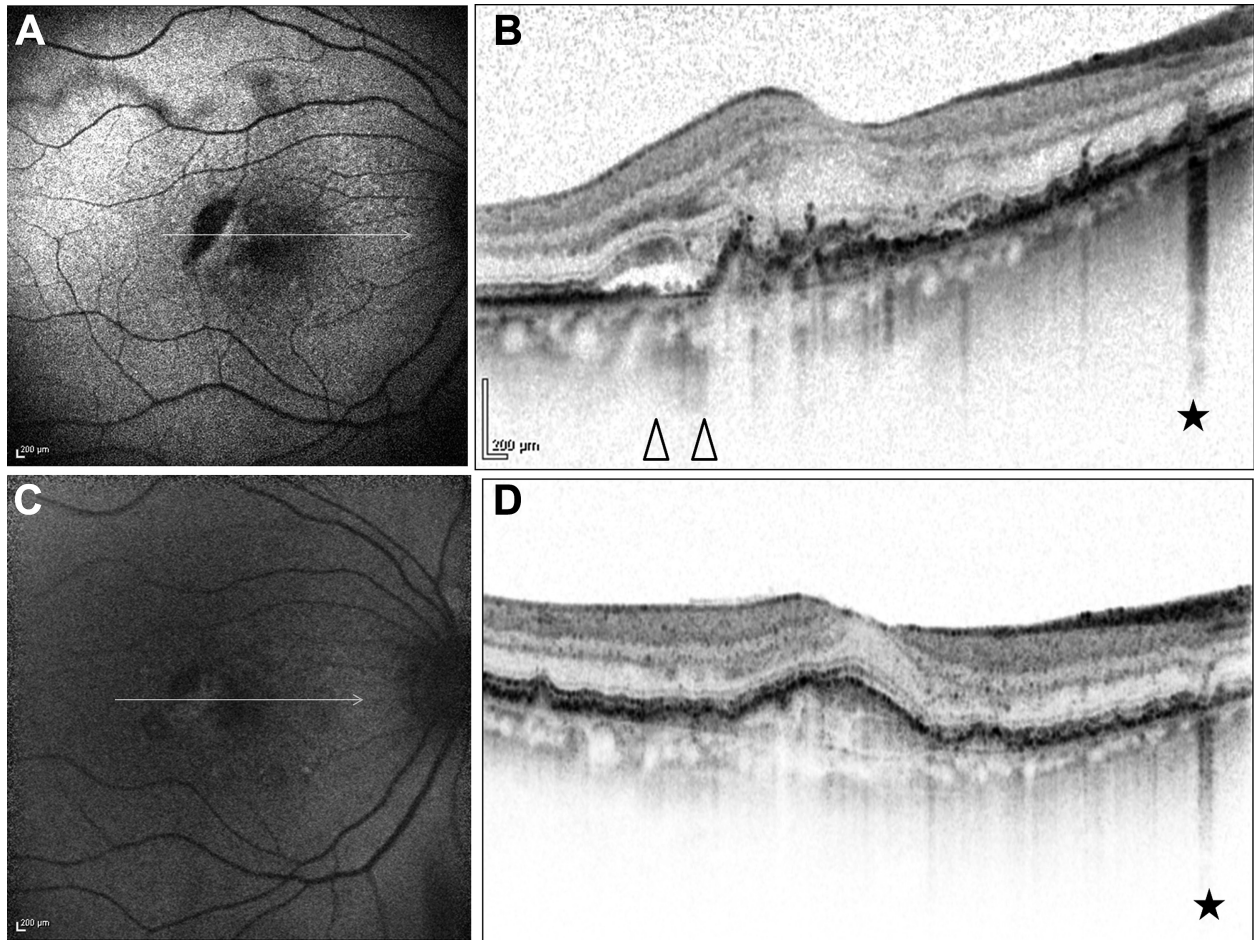
membrane of the flap tear (cf, figure 15 in Green et al). ${ }^{11}$ Although RPE proliferation might theoretically lead to a functional RPE layer, this proliferation is not directed. ${ }^{11}$ In our study, we found misdirected RPE migration into the retina, which possibly did not lead to a functional RPE layer supporting the photoreceptors.

Intraretinal RPE cell migration has been described in various retinal diseases, for example, retinitis pigmentosa, congenital RPE hypertrophy ${ }^{12}$ or early to late dry age-related macular degeneration. ${ }^{13-16}$ In OCT images, migrating intraretinal RPE cells are hyper-reflective lesions with high backscattering and appear as hyperfluorescent areas in FAF. Other structures, such as hard exudates, may also appear as HRDs in SD-OCT, ${ }^{17}$ but appear as hypofluorescent lesions in FAF (figure 3). The origin of migrated RPE cells seen in this study is unclear; there is a possibility also that these cells are remnants of RPE cells attached to the photoreceptors left from the traumatic event of the RPE tear. In course of time due to lack of suitable scaffolding structures, they migrate into the retina. Individual cells might also proliferate into clumps, which are then big enough to be detected using FAF. This mechanism is however speculative.

RPE cells migrate towards various chemokines and cytokines, such as tumour necrosis factor $\alpha$ or interleukin $1{ }^{18-21}$ After the acute event of an RPE tear, it is likely that such chemo attractants are secreted. Nevertheless, it is unclear why certain RPE cells remain in the level of Bruch's membrane and why others migrate into the retina. One possible explanation might be the absence of scaffolding structures, which are important for RPE cells for proliferation.

Some authors described small RPE tears where the RPE denuded area became covered by a layer of relatively normallooking, hypopigmented RPE derived from cells from the margin of the defect. ${ }^{22} 23$ We also documented a case with a small RPE tear, where RPE cells migrated and covered the defect. This healing property might not be enough for large RPE tears. In $41.7 \%$ (15 eyes) of all cases, we identified a homogenous subretinal mass in the RPE denuded area. This substance may represent fibrin or proliferated RPE cells. Nevertheless, this subretinal mass failed to build a single layer, which is a prerequisite for RPE cell function in terms of ion and fluid transport. ${ }^{24}$ In our study, only in $2.8 \%$ of cases RPE cells could fully cover the defect.

Animal studies of retinal pigment epithelial wound healing in rabbits $^{25}$ and monkeys ${ }^{26}$ suggested that newly proliferated RPE cells are hypopigmented. In our study, we also saw a hypofluorescent RPE layer in FAF. We hypothesise that these new RPE cells originate from old RPE cells from tear border. But since by means of mitosis cells also give about half of their cytoplasm to the new cells, they have only about half as many lipofuscin as their original cells. Therefore, they emit less FAF signal. Although not shown in this study, it is logical to assume these new RPE cells will also accumulate lipofuscin over time as well.

There are some limitations in this study, such as the retrospective nature of the study prone to bias of uncertain kind and a relatively small number of patients. However, giving the fact that RPE tears are rare, we presented a relatively large number of patients observed. Also by combining FAF and SD-OCT we are able to observe RPE tears more efficiently.

We observed in this study 12 patients with RPE tear grade 1 or 2 ; however, only one patient showed self-healing mechanism. Although the exact reason is speculative, there are in vitro studies suggesting that RPE cells proliferation is dependant of $\operatorname{age}^{27}$ and health of the scaffolding structure (Bruch's membrane). ${ }^{28}$ We hypothesise that the patient with a self- healing RPE tear might have a relatively undamaged Bruch's membrane after the traumatic event, allowing the RPE cells to repopulate the area. Using current in vivo technologies, however, the health of Bruch's membrane cannot be easily assessed.

In conclusion, there is a chance that small RPE tears are populated by RPE cells, and so waiting might be appropriate. As shown previously, photoreceptors in the RPE denuded area are able to survive up to 325 days after the acute event; ${ }^{2}$ we propose therefore to continue anti-vascular endothelial growth factor therapy to slow down scar progression, to protect the photoreceptors from further damage (unpublished data) and giving the chance of self-healing. In large RPE tears, however, RPE proliferation and migration might not happen in the right plain, which is under the photoreceptors. In these cases, therapies aiming at RPE layer replacement, such as in macular translocation or autologous RPE and choroid transplantation can offer help. Although we are not able to predict which patient has the greatest chance of self-healing, because only one patient in this study showed self-healing, knowing the facts that photoreceptors will survive up to 325 days $^{2}$ and there is a chance of self-healing of small RPE tears, we propose that therapies aiming at RPE layer replacement do not have to be performed as an emergency procedure. In fact, such risky procedures can be planned and offered, if after waiting the self-healing properties have been proven to be insufficient.

Contributors Conception, design and data acquisition: AC. Data analysis and interpretation: AC, SF, BK. Drafting and revising the article: AC, SF. BK. Final approval: $A C, S F, B K$.

Competing interests None.

Patient consent Obtained.

Provenance and peer review Not commissioned; externally peer reviewed.

\section{REFERENCES}

1. Caramoy A, Kirchhof B, Fauser S. Morphological versus functional photoreceptor viability of retinal pigment epithelium tears. Acta Ophthalmol 2012;90:e328-9

2. Caramoy A, Kirchhof B, Fauser S. Retinal pigment epithelium tears secondary to age-related macular degeneration: a simultaneous confocal scanning laser ophthalmoscopy and spectral-domain optical coherence tomography study. Arch Ophthalmol 2011;129:575-9.

3. Gelisken F, Karim-Zoda K, Grisanti S, et al. Macular translocation with 360 degrees retinotomy for retinal pigment epithelial tear. Graefes Arch Clin Exp Ophthalmol 2005;243:619-21.

4. Polito A, Cereda M, Romanelli F, et al. Macular translocation with 360 degrees retinotomy for management of retinal pigment epithelial tear: long-term results. $\mathrm{Br} \mathrm{J}$ Ophthalmol 2011;95:74-8.

5. Caramoy A, Fauser S, Kirchhof B. Retinal stimuli can be restored after autologous transplant of retinal pigment epithelium and choroid in pigment epithelium tears. Acta Ophthalmol 2011:89:e490-5.

6. Maaijwee K, Joussen AM, Kirchhof B, et al. Retinal pigment epithelium (RPE)choroid graft translocation in the treatment of an RPE tear: preliminary results. $\mathrm{Br} J$ Ophthalmol 2008;92:526-9.

7. Pece A, Vitale L, Milani P, et al. Spontaneous reattachment of the margins of a macular retinal pigment epithelium tear: optical coherence tomography documentation of a case. Ophthalmologica 2010;224:159-61.

8. Peiretti E, Iranmanesh R, Lee JJ, et al. Repopulation of the retinal pigment epithelium after pigment epithelial rip. Retina 2006;26:1097-9.

9. Sarraf D, Reddy $S$, Chiang $A$, et al. A new grading system for retinal pigment epithelial tears. Retina 2010;30:1039-45.

10. Chuang EL, Bird AC. Repair after tears of the retinal pigment epithelium. Eye (Lond) 1988;2:106-13.

11. Green WR, McDonnell PJ, Yeo JH. Pathologic features of senile macular degeneration. Ophthalmology 1985;92:615-27.

12. Schneider S, Green WR. Congenital and Acquired Lesions of the Retinal Pigment Epithelium. Retinal Pigment Epithelium and Macular Diseases. Dordrecht, The Netherlands: Kluwer, 1998:69-80.

13. Ho J, Witkin AJ, Liu J, et al. Documentation of intraretinal retinal pigment epithelium migration via high-speed ultrahigh-resolution optical coherence tomography. Ophthalmology 2011;118:687-93.

14. Schuman SG, Koreishi AF, Farsiu S, et al. Photoreceptor layer thinning over drusen in eyes with age-related macular degeneration imaged in vivo with spectral-domain optical coherence tomography. Ophthalmology 2009;116:488-96.e2. 
15. Fleckenstein $\mathbf{M}$, Charbel Issa $\mathrm{P}$, Helb HM, et al. High-resolution spectral domainOCT imaging in geographic atrophy associated with age-related macular degeneration. Invest Ophthalmol Vis Sci 2008;49:4137-44.

16. Pieroni CG, Witkin AJ, Ko TH, et al. Ultrahigh resolution optical coherence tomography in non-exudative age-related macular degeneration. $\mathrm{Br} \mathrm{J}$ Ophthalmol 2006;90:191-7.

17. Ota M, Nishijima K, Sakamoto A, et al. Optical coherence tomographic evaluation of foveal hard exudates in patients with diabetic maculopathy accompanying macular detachment. Ophthalmology 2010;117:1996-2002.

18. Jin M, He S, Worpel V, et al. Promotion of adhesion and migration of RPE cells to provisional extracellular matrices by TNF-alpha. Invest Ophthalmol Vis Sci 2000:41:4324-32.

19. Mitsuhiro MR, Eguchi S, Yamashita H. Regulation mechanisms of retinal pigment epithelial cell migration by the TGF-beta superfamily. Acta Ophthalmol Scand 2003;81:630-8.

20. Hogg PA, Grierson I, Hiscott P. Direct comparison of the migration of three cell types involved in epiretinal membrane formation. Invest Ophthalmol Vis Sci 2002;43:2749-57.
21. Han $\mathbf{0 H}$, Hui YN, Du HJ, et al. Migration of retinal pigment epithelial cells in vitro modulated by monocyte chemotactic protein-1: enhancement and inhibition. Graefes Arch Clin Exp Ophthalmol 2001;239:531-8.

22. Hoskin A, Bird AC, Sehmi K. Tears of detached retinal pigment epithelium. $\mathrm{Br} \mathrm{J}$ Ophthalmol 1981;65:417-22.

23. Chang LK, Sarraf D. Tears of the retinal pigment epithelium: an old problem in a new era. Retina 2007;27:523-34.

24. Sparrow JR, Hicks D, Hamel CP. The retinal pigment epithelium in health and disease. Curr Mol Med 2010;10:802-23.

25. Lopez PF, Yan 0, Kohen L, et al. Retinal pigment epithelial wound healing in vivo. Arch Ophthalmol 1995;113:1437-46.

26. Valentino TL, Kaplan HJ, Del Priore LV, et al. Retinal pigment epithelial repopulation in monkeys after submacular surgery. Arch Ophthalmol 1995;113:932-8.

27. Stanzel BV, Blumenkranz MS, Binder S, et al. Longterm cultures of the aged human RPE do not maintain epithelial morphology and high transepithelial resistance. Graefes Arch Clin Exp Ophthalmol 2012;250:313-15.

28. Binder S. Scaffolds for retinal pigment epithelium (RPE) replacement therapy. $\mathrm{Br} \mathrm{J}$ Ophthalmol 2011;95:441-2 